\title{
A Composite Leading Indicator of the Inflation Cycle for the Euro Area
}

\author{
JM Binner $^{1}$, RK Bissoondeeal ${ }^{2}$, AW Mullineux ${ }^{3}$ \\ ${ }^{1}$ Strategic Management Group, Aston Business School, Birmingham, B4 7ET, UK \\ Email: j.m.binner@ aston.ac.uk \\ Tel : 44 (0) 1213593611 Ext: 4425 \\ Fax: 44 (0) 1213333474 \\ ${ }^{2}$ Department of Information Management \& Systems, \\ The Nottingham Trent University, Nottingham, NG1 4BU, UK \\ Email: rakesh.bissoondeeal@ntu.ac.uk \\ Tel: +44 (0) 1158484089 \\ Fax: +44 (0) 1158484707 \\ ${ }^{3}$ Department of Accounting and Finance, Birmingham Business School, \\ The University of Birmingham, Birmingham, B15 2TT, UK \\ Email: A.W.MULLINEUX@bham.ac.uk \\ Tel: +44 (0) 01214146642 \\ Fax: +44 (0) 01214146678
}

Corresponding Author: Jane M. Binner

Running title: A Composite Leading Indicator of Inflation

\begin{abstract}
We evaluate the performance of composite leading indicators of turning points of inflation in the Euro area, constructed by combining the techniques of Fourier analysis and Kalman filters with the National Bureau of Economic Research methodology. In addition the paper compares the empirical performance of Euro Simple Sum and Divisia monetary aggregates and provides a tentative answer to the issue of whether or not the UK should join the Euro area. Our findings suggest that, firstly, the cyclical pattern of the different composite leading indicators very closely reflect that of the inflation cycle for the Euro area; secondly, the empirical performance of the Euro Divisia is better than its Simple Sum counterpart and thirdly, the UK is better out of the Euro area.
\end{abstract}




\section{Introduction}

Financial market participants and policymakers such as the European Central Bank (ECB) are heavily dependent on forecasts of inflation and its turning points as such information allows them to adjust their calculations of the future economic environment. In this paper we focus on inflation turning point forecasts for the Euro area; inflation forecasts are looked at in a different paper co-authored by the current authors (see Binner et al. (2005)). Despite advances in mathematical and statistical techniques, a reliable method to forecast inflation turning points has continued to evade forecasters. Consequently, interest in the use of composite leading indicators (CLIs) of inflation turning points has been heightened. These are constructed from a group of time series variables which have cycles which resemble the turning points in the inflation cycle but whose turning points precede the turning points in the inflation cycle.

The leading indicator approach was developed by the National Bureau of Economic Research (NBER) and was popularised by the work of Burns and Mitchell (1946) in the US. This approach has since been utilised in a number of studies, but mostly applied to business cycles. Application to the inflation cycle is relatively new and much of the literature is related to the US (see, for example, Roth (1991) and Boughton and Branson (1991)). A few European studies exist (see, for example, Artis et al. (1995) and Binner et al. (1999) for the UK and Bikker and Kennedy (1999) for seven EU countries) but to the best of our knowledge no study has been carried out to develop CLIs of inflation for the Euro area. One of the main objectives of this paper, therefore, is to develop CLIs of inflation for the Euro area and to assess their forecasting performance. 
Even though the leading indicator approach has been rather successful in providing early information about future turning points, it is widely believed that the way leading indicators are constructed is crude and does not look rigorous in terms of criteria commonly applied in modern econometrics. For example in the UK, a recent research project supported jointly by the Central Statistics Office and HM Treasury was designed to investigate possible alternatives to the existing methods of constructing leading indicators which form the basis of most official published leading indicators (Salazar et al., 1995). Recently, time series techniques of Fourier analysis and Kalman filters have been used in the construction of CLIs and the resulting CLIs were found to offer considerable improvement over the traditionally constructed indicators (see Binner and Wattam (2003)). Therefore, following the seminal work of Binner and Wattam (2003), we use Fourier analysis and Kalman filters to develop more sophisticated CLIs of inflation turning points for the Euro area.

To increase the relevance of this paper to policymakers we have two further aims in the paper. Firstly, to evaluate the relative performance of Euro area Simple Sum and Divisia monetary aggregates in the CLI of inflation framework, in view of the prominent role of monetary aggregates in the current monetary policy strategy of the ECB. See ECB (1999a, b and 2000) for an overview of the use of monetary aggregates in the Euro area and, for example, Selertis and Atkins (1988) and Gazely and Binner (2000) for the motivation of comparing Divisia aggregates against Simple Sum aggregates with a view to considering them for monetary policy purposes. For recent debates on the construction of Divisia aggregates, see, for example, Ford and Morris (1996) and Elger and Binner (2004). A few Euro area studies exist which compare the empirical performance of the Simple Sum and Divisia aggregates, see for example Drake et al. (1997) and Stracca (2004), but in most cases the monetary 
indices are compared in a money demand framework. To the best of our knowledge, no study exists for the Euro area which compares the Simple Sum and Divisia indices in a CLI of inflation turning point framework. Hence, the motivation to perform such a comparison. The second additional aim is to provide a tentative answer to the issue of whether or not the UK should join the Euro area. This investigation is based on graphical analysis and the CLI of inflation framework. For the latter, we first construct UK CLIs with economic series considered to have ample information for future UK inflation turning points. Then we construct Euro-based UK CLIs, i.e. indicators constructed with appropriate Euro area inflation cycle turning point CLIs as components, in addition to component series of UK CLIs. Graphical analysis and comparison of the correlations of the aforementioned CLIs with the UK inflation cycle will be used to provide a tentative answer on the issue of whether or not the UK should join the Euro area.

The remainder of the paper is organised as follows. The next section presents the data and outlines the methodology used. Section 3 analyses the results and provides a short discussion on whether or not the UK should join the Euro area. Finally Section 4 provides a summary and the conclusions.

\section{Methodology and Data}

The prevailing methodology used in constructing leading indicators for economic activity is still very similar to that established by the NBER in the 1930s and 1940s. Applied to inflation cycles it consists of the following major steps:

(1) Firstly the turning points of the inflation cycle are identified.

(2) Secondly appropriate economic and financial variables which contain information about future inflation turning points are selected. This is normally done in two stages. 
In the first stage, a large number of series are chosen which are considered to have a theoretical leading relationship with the inflation series ${ }^{\mathrm{i}}$. In the second step, only those series are chosen whose turning points predate those of the inflation series.

(3) Thirdly composite leading indicators are constructed and their performance evaluated.

For the construction of Euro CLIs of inflation we are, however, unable to proceed exactly in the above described traditional manner. More specifically, instead of choosing the component series of the CLIs as described in step 2, a more subjective technique is used. This is because the Euro area has come into existence only recently and therefore the set of component series from which a selection can be made is very limited. Moreover, some of the series that do exist are available for a limited historical period. Therefore, instead, the series that we use are those that are both available and that have been very successfully used in previous studies for constructing CLIs of inflation for European countries (see, for example, Bikker and Kennedy (1999), Binner and Wattam (2003), Artis et al. (1995)). For the UK, we use the series used by Binner and Wattam (2003), most of which have been previously identified as leading indicators of inflation turning point by Artis et al. (1995) using the criteria described in step 2 above. Tables 1 and 2 contain the list of series used in the construction of CLIs, for the period 1980 to 1998 , for the Euro area and the UK respectively. The starting and ending periods of the data sample are constrained by the availability of Euro area data taken from the Euro area studies of Stracca (2004) and Fagan et al. (2001). Monthly data are preferred in the construction of CLIs and this is often a criterion for selecting component series of CLIs. This is because the more data points are observed, the closer the cycle can be captured and the better the possibilities of, for example, dating the turning points. However, some of the data are only available 
as quarterly series and the Euro area data made available to us were quarterly data. In these cases, we have converted the quarterly data into monthly data using linear interpolation following the Organisation for Economic Co-operation and Development (OECD) which does so while constructing leading indicators of business cycles for its member countries. For the construction of the inflation series ${ }^{\text {ii }}$, the GDP deflator is used for the Euro area while RPI is used for the UK.

In addition to our slightly different approach for constructing CLIs, we also add value to NBER methodology by using Fourier analysis and Kalman filters. Fourier analysis is used for modelling the cyclical components of the series under investigation while the Kalman filter algorithm is used to extract the inflation turning point signal from 'crude' forms of CLIs. The latter are constructed by aggregating the modelled individual cyclical components. These techniques have been previously used in constructing CLIs by Binner and Wattam (2003) and the resulting CLIs were found to considerably outperform traditionally constructed CLIs.

\section{[Tables 1 and 2 about here]}

\subsection{Derivation of Cycles}

Cycles are an abstract concept and are not observable in reality. Therefore, to measure cycles, they must first be defined. In general, cycles are defined in two ways- classical cycles and deviation from trend cycles. Classical cycles refer to declines and rebounds in the level of economic series, whereas deviation cycles refer to deseasonalized, smoothed series expressed as the deviation from its long term trend. Most leading indicators are based on deviation cycles, as classical cycles are sometimes very difficult to identify because the fluctuations in many economic series appear to be dominated by strong trends. Therefore, in this study we chose to work with deviation cycles to construct our leading indicators. 
Generally, it may be assumed that an observed univariate additive $\mathrm{iii}^{\mathrm{ii}}$ time series $y_{t}$ is the sum of four unobserved components, namely the cycle $\left(C_{t}\right)$, seasonal $\left(S_{t}\right)$, trend $\left(T_{t}\right)$, and irregular components $\left(I_{t}\right)$, i.e., can be represented as

$$
y_{t}=C_{t}+S_{t}+T_{t}+I_{t}
$$

Adopting the deviation cycle approach the cyclical components can be obtained by subtracting the seasonal, trend and irregular components from $y_{t}$.

The seasonal and irregular components do not permit a clear vision of the cyclical behaviour and are normally filtered out first. The very commonly used Census X-12 procedure, developed by the US Bureau of Census, is used to capture these components ${ }^{\mathrm{iv}}$. The Census $\mathrm{X}-12$ procedure is essentially a combination of moving averages. Many detrending techniques exist to remove the trend; however, it is very difficult to know which one is the most appropriate. Each one is relevant in certain circumstances and has its own implications. Canova (1999) examined the sensitivity of the turning points classification to different detrending methods and the ability of each to replicate the NBER dating of business cycles. The Hodrick-Prescott filter (HP) (Hodrick and Prescott (1997)) and the frequency domain filters (Baxter and King (1999)) methods were found to be the most reliable methods to closely reproduce the NBER classifications. However, empirically, HP is the most extensively used technique and has the advantage of being a built-in command in Eviews. We therefore opt for the HP detrending technique in this study. The HP filter extracts the trend component by solving a programming problem in which $\lambda$ is a positive number controlling the variation of the trend (see, Hodrick and Prescott (1997)). The larger the value of $\lambda$ the smoother is the solution series. In the extreme case as $\lambda \rightarrow \infty$, the trend approaches a linear time trend. The optimal value of $\lambda$ depends on the time series and may be derived by means of a 'signal extraction- 
prediction error decomposition' technique (see, den Butter, Coenen and van de Gevel (1985) for more information on this technique). Most empirical work, however, simply assumes a particular value for $\lambda$. Thus, following a suggestion of Serletis and Kraus (1996) we set $\lambda$ to 129600 as this value approximately averages to the quarterly components defined by $\lambda=1600$ which is commonly used to define business cycle fluctuations in the research literature. Application of the HP filter with the aforementioned specification results in nonlinear trends for all series under consideration, not shown here for reasons of brevity.

\subsection{Dating Cyclical Turning Points}

The next issue is what criteria to use to date the turning points of the cyclical components. Bodies like the NBER and Central Statistics Office provide reference chronologies for business cycles but no reference chronologies exist for inflation cycles. Artis et al. (1995), however, have devised some ground rules for dating inflation turning points and despite their simplicity, they seem to capture well the turning points of inflation in studies where they have been used (see, for example, Binner et al. (1999). Therefore in this study also we use the rules devised by Artis et al. (1995) which are as follows. First, is the obvious requirement that peaks will always follow troughs and vice versa. Second, the duration of an upswing or downswing regime should be at least nine months in order to satisfactorily capture medium term movements in inflation. Third, a turning point is the most extreme value between two adjacent regimes and fourth, if there are two or more equal values satisfying the first three requirements, the most recent one is chosen as the turning point of the regime. The same rules are applied in dating the turning points in the cycles of the inflation series and each of the indicator series. The number of cycles 
identified in each case is given in Tables $3 \mathrm{a}$ and $3 \mathrm{~b}$ for the Euro area and the UK respectively.

\subsection{Fourier Analysis of Cyclical Components and Timing Classification of}

\section{Indicators}

In this section the cyclical components are modelled using Fourier analysis. The mathematical Fourier Theorem states that periodic data, like cyclical components of time series, can be expressed as the sum of a series of sine or cosine terms. If assumed that the periodic data consist of a single cosine wave, like in Binner and Wattam (2003), then they can be represented as

$$
C_{t}=\mu+R \cos (\omega t+\phi)+\varepsilon_{t}, \quad t=0,1, \cdots, n-1,
$$

where $n$ is the number of observations, $\mu$ is a constant, $R$ the amplitude, $\omega=2 \pi p / n$, is the frequency, where $p$ is the number of cycles and $\phi$ is the phase of the wave and $\varepsilon_{t}$ is the $t^{\text {th }}$ residual. The unknown parameters here are $\mu, R$, and $\phi$ and their estimation becomes less cumbersome if Equation 2 is reformulated as

$$
C_{t}=\mu+A \cos \omega t+B \sin \omega t+\varepsilon_{t}
$$

where $A=R \cos \phi$ and $B=-R \cos \phi$. Estimates of $\mu, A$, and $B$ can be obtained from the following equations (Bloomfield, 1976).

$$
\begin{aligned}
& \tilde{\mu}=\tilde{C}=(1 / n) \sum C_{t} \\
& \tilde{A}=(2 / n) \sum\left(C_{t}-\tilde{C}\right) \cos \omega t \\
& \tilde{B}=(2 / n) \sum\left(C_{t}-\tilde{C}\right) \sin \omega t
\end{aligned}
$$

Given the estimates of $A$ and $B$, we may solve for $R$ and $\phi$. The basic equation for $\phi$ is $\tan \phi=-B / A$. However, the solution $\phi=\tan ^{-1}-B / A$ is incorrect as it gives the same 
values for $-A$ and $-B$ as for $A$ and $B$. The full solution is obtained from the solution set given in Bloomfield (1976).

After the cyclical components of the different series have been modelled using Fourier analysis, the modelled cycles are normalized to make them comparable and to avoid the series with the greatest amplitudes in their cycles exerting too much influence on the composite indicator. Normalization involves setting the means of the Fourier generated cycles to zero and their standard deviations to one. The series are then expressed in index-number form by adding 100 to them.

The modelled cycles of the indicator series are then compared to that of the inflation series. The resulting lead times in months were calculated by visual inspection and subsequently the standard deviations were also calculated. These values are also given in Tables $3 \mathrm{a}$ and $3 \mathrm{~b}$ for the Euro area and the UK respectively. For example, Real Simple Sum M3, in Table 3a, has a 3 months warning over the next turning point (either peak or trough) in the inflation series; the standard deviation around this mean is 0.4 months. From Tables $3 \mathrm{a}$ and $3 \mathrm{~b}$ it can be seen that 20 months is a natural borderline between the various lead times achieved. Hence 20 months and below were chosen to represent short leading indicators, whilst leads above 20 months were assumed to be longer leading indicators.

\section{[Tables 3a, b about here]}

From Tables $3 \mathrm{a}$ and $3 \mathrm{~b}$ the average lead for composite short term and long term indicators were set at 15 and 29 months respectively, whilst Divisia and Simple Sum indices were classified as both short and long term indicators for experimental purposes. Before constructing composite leading indicators the individual leading indicators are lagged according to the average lead times. 
There are various ways of combining the leading indicator series into a composite leading indicator. One of the simplest techniques, as used in, for example, Artis et al. (1995) is by simple averaging. It has been argued that such a method, however, is essentially arbitrary as it is neither data driven nor theory driven (Binner et al., 1999). For this reason, Binner et al. (1999) have derived the appropriate weight for each component using the principal components method, which assumes that the first principal component of the leading indicator series, which explains as much as possible of the variation of the leading indicator series, may be taken to represent the inflation series (see, for example, Bikker and Kennedy (1999)). In this study for every CLI, the component series are aggregated using both simple averaging (that is giving equal weights (of unity) to each of the component series) and weights derived from principal component analysis. However, we only present the CLIs resulting from whichever aggregation technique that shows a closer relationship with the inflation cycles.

When the individual leading indicator series are combined, the CLIs do not closely resemble the inflation cycle and in some cases there are false signals of turning points. The disagreement between the CLIs and the inflation cycle is due to the undue influences of some turning points from some of the individual leading indicator series. Therefore, the true signal for inflation turning points has to be separated from unwanted information. For this purpose State Space models and Kalman filters can be used (see, for example, Harvey (1991) ans Chatfield (1996)), to which we turn to in the next section. These techniques have been very successfully applied in extracting the inflation cycle turning points from the 'crude' form of CLIs by Binner and Wattam (2003). 


\subsection{State Space Models and Kalman Filters}

Given an observed time series $x_{t}$ which can be described by a possibly unobserved $\boldsymbol{( n \times 1}$, vector $\boldsymbol{\theta}_{t}$ known as the state vector, then a State Space model can be represented by the following equations.

$$
\begin{gathered}
x_{t}=\mathbf{h}_{t}^{T} \boldsymbol{\theta}_{t}+\eta_{t} \\
\boldsymbol{\theta}_{t}=\mathbf{G}_{t} \boldsymbol{\theta}_{t-1}+\mathbf{w}_{t}
\end{gathered}
$$

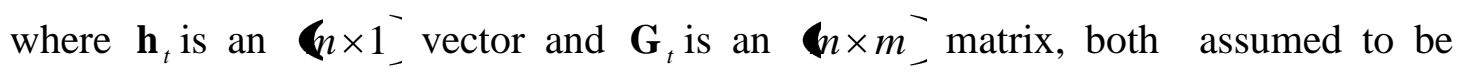
known. $\eta_{t}$ and $\mathbf{w}_{t}$ denote the observation errors which are assumed to be independent and white noise. Equation 5 is usually referred to as the observation (measurement) equation and Equation 6 the state (or transition) equation. Though $\boldsymbol{\theta}_{t}$ is unobserved, it is generally assumed that $\boldsymbol{\theta}_{t}$ is generated by a first order autoregressive process.

The State Space form is a powerful tool that opens the way for the application of a number of important algorithms for estimating the unobserved vector $\boldsymbol{\theta}_{t}$. One very popular algorithm for doing this is the Kalman filter, which is described in, for example, Harvey (1991) and Chatfield (1996).

\section{Performance of Composite Leading Indicators and Discussions}

The correlations of the Kalman generated Euro CLIs against the inflation reference cycle are given in Table 4. It can be seen from these results that on the whole the cyclical patterns of the different CLIs are rather similar and closely reflect the cycles in the inflation series. These findings demonstrate that CLIs are a useful and powerful alternative to statistical methods for forecasting turning points of inflation. Implicit in the findings is the fact that techniques like Fourier analysis and Kalman filters can be used for constructing very sophisticated CLIs of inflation. 
When the results are examined in greater detail, firstly, the longer CLIs are found to be more closely related to the inflation cycle. Secondly, CLIs that incorporate Divisia monetary indices show a stronger relationship to the inflation cycle than CLIs based on Simple Sum monetary indices. This result suggests that Divisia monetary indices would provide earlier warning of impending inflation than their Simple Sum counterparts. It may also be concluded that the simple summation way of constructing aggregates is flawed and therefore Divisia aggregates would be more appropriate than Simple Sum aggregates as a guide for the monetary policy strategy for the ECB.

\section{[Table 4 about here]}

The difference between the Kalman generated Euro CLIs and the inflation reference cycle was compared and checked for residual autocorrelation, these results are also presented in Table 4. The Durbin Watson test appears to indicate that autocorrelation is present in the residuals, which suggests that observed time series have more periodic features in them than can be detected by the dating rules employed here and the equation used to model them in this paper. It might also suggest that the phase of the CLIs is out of synchronisation with the inflation reference cycle. However, graphical inspection of the CLIs plotted against the inflation reference cycle suggests that the cycles are very closely synchronised. For example, Figure A.1 in Appendix A illustrates the close synchronisation between the DM3 Long indicator and the inflation cycle. Moreover, the prediction error covariance ${ }^{\mathrm{v}}$, decreases asymptotically rapidly, which is indicative of the adequacy of Kalman generated CLIs.

There is an ongoing debate on whether or not the UK should join the Euro area. The opinions of the public, businesses and professional economists are divided on this issue. However, at present it seems that joining the Euro area does not seem to 
be a very popular action. From an economist's perspective, one of the major concerns is membership to the Euro area would most probably deprive the UK of an independent monetary policy, that is, the Bank of England will have no say in the monetary policy, which will be carried out by policymakers at the ECB. The problem for many economists is the lack of credibility of the ECB. In contrast to the Bank of England which has become very credible because of its record on inflation, the procedures of the ECB are much less transparent and its objectives less clear and the ECB is felt not to have performed so well. This results in a lack of confidence in the Euro in comparison with Sterling. Many economists also allude to the experience of Britain in the Exchange Rate Mechanism (ERM). During its ERM membership, October 1990 to September 1992, when Britain had contracted out its monetary policy to Europe, it suffered its worst recession, as measured by total output lost, in sixty years, unemployment doubled, three-quarters of a million homes were thrown into negative equity and 100,000 businesses went bankrupt. But once the UK left the ERM, its economy recovered immediately. Leaving the ERM proved to be a blessing for the UK, however, Euro membership is irrevocable and there is no guarantee of success. Therefore the UK, which is the world's fifth largest economy, has to be extremely cautious for every step it takes towards the Euro. This is the case at the moment, as the UK has not yet joined the Euro area as four of the five tests, introduced by the Chancellor of the Exchequer of Britain to analyse the possibility of Britain joining the Euro, have failed. In this paper we try to provide some further tentative evidence on whether or not the UK should join the Euro area.

Firstly on comparing the number of cycles in Tables $3 a$ and $3 b$, it can be noticed that in the majority of cases, the number of cycles in the Euro area series is higher than in their UK counterparts, implying that the UK economic cycles will be 
out of phase with those of the Euro area. This finding is consistent with those of studies like Artis and Zhang (1999), Artis et al. (1999) and Barrios et al. (2002). The UK inflation series being out of phase with the Euro area inflation series, as shown in Figure A.2 in Appendix A, is of even greater interest from a monetary-policy viewpoint. It can be seen that there are times when the UK economy enters recession the Euro area economy enters recovery and vice versa. If the UK unites with the Euro area and such divergences were to occur in the future, the UK would have to endure interest rates that are quite inappropriate to the phase of the UK economic cycle. More specifically, if for example the UK is still in recession but the Euro area economy is growing, the ECB would certainly want to raise interest rates, to slow down the Euro area boom. Such an action could bring the UK economy further down. On the other hand if the UK economy is growing fast while the Euro area economy is in recession, the ECB might want to cut interest rates. Such an action could have a disastrous effect on the British economy- for example this could fuel a house price explosion. Therefore, the initial conclusion is that the UK should not join the Euro area. However, the diverging behaviour of UK and Euro inflation cycles could be due to different macroeconomic policies. Membership of the UK to the Euro area might force the cycles to converge.

The CLIs in Table 5a consist of economic series which are considered to have UK inflation information content and will be referred to as UK CLIs. The CLIs in Table 5b, in addition to containing the component series of their UK CLIs counterparts, also consists of appropriate CLIs of the inflation turning point for the

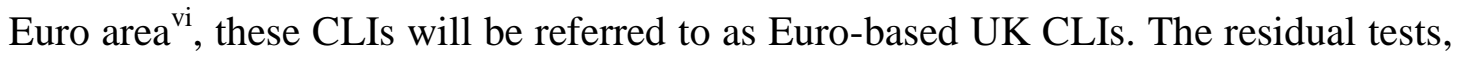
also, given in Tables $5 \mathrm{a}$ and $5 \mathrm{~b}$ are based on residuals obtained from the models in these tables. Here also the residual tests indicate that presence of autocorrelation, but a 
graphical inspection suggests that the cycles of the indicators and that of inflation are not out of synchronisation and the prediction error covariance of each model decreases asymptotically. On comparing the corresponding CLIs (for example, SM4 Short from Table 5a is compared to SM4 Short in Table 5b), it is found that all the CLIs from Table 5a show a closer relationship to the inflation cycle than those in Table 5b. Such a finding suggests that Euro area series with information content about the Euro area inflation do not help in constructing superior CLIs for UK inflation. Therefore the conclusion we draw from our finding is that, if the UK unites with the Euro area, ECB measures to combat inflationary pressures might not have the same corrective effect on the UK as would measures taken based on future UK inflation information. Therefore we can tentatively conclude that the UK would be better off on its own as long as it pursues a sensible monetary policy strategy. This reinforces our initial conclusion based on graphical inspection.

\section{[Tables 5a, b about here]}

\section{Summary and Conclusions}

In this paper short and long composite leading indicators of the inflation turning points for the Euro area are constructed using Fourier analysis and Kalman filters. Empirical performances of Simple Sum and Divisia aggregates are also compared in the composite leading indicator framework. The same framework and graphical analysis are also used to provide a tentative answer to the issue of whether or not the UK should join the Euro area.

On the whole the cyclical patterns of the different CLIs are rather similar and closely reflect the cycles on the inflation series. Such a finding suggests that Fourier analysis and Kalman filters can be combined with the traditional NBER methodology to construct sophisticated CLIs. The finding also lends support to the similar seminal 
study for the UK carried out by Binner and Wattam (2003). It is also of great importance to policymakers and should form the basis of future research for constructing leading indicators of inflation cycle or business cycles.

Regarding the appropriate use of monetary aggregates for policy purposes in the Euro area, the results suggest that the Divisia indices appear to offer advantages over simple sum indices as macroeconomic indicators. The Divisia-based CLIs are found to be more closely related to the inflation cycle than Simple Sum-based CLIs. This finding is consistent with earlier evidence provided by Binner et al. (1999) and Binner and Wattam (2003). These findings therefore suggest that the behaviour of the Divisia monetary aggregate should be taken more seriously by both policy makers and academics. It may be concluded that a money stock mismeasurement problem exists and that the technique of simply summing assets in the formation of monetary aggregates is inherently flawed.

Based on findings from graphical analysis and CLI analysis it might also be concluded that the UK is better out of the Euro area as the monetary policy strategy of the ECB to maintain price stability in the Euro area might not be stabilising for the UK. Our findings corroborate those of Bhattacharya and Binner (1998), 'unless a convincing empirical case can be made that there are likely to be substantial economic benefits from monetary union over the next few years to offset this loss of a monetary policy tool, the evidence presented here suggests that there is a strong economic case for proceeding with monetary union with extreme caution'. However, membership of the UK to the Euro area might lead to converging behaviour of inflation cycles and economic cycles and hence the ECB's monetary policy strategy could have the desired effect on the UK economy. 


\section{Acknowledgements}

The authors gratefully acknowledge the help of Mr Livio Stracca and Mr Jérôme Henry and Alistair Dieppe from the European Central Bank for making the Euro area data available to us and Mr Anindya Banerjee at the European University Institute for his help in directing us to the potential sources of the Euro area data. Mr Stuart Wattam is also gratefully acknowledged for his help and comments on this paper.

\section{References}

Artis, M.J., and Zhang, W. (1999) Further evidence on the international business cycle and the ERM: Is there a European business cycle? Oxford Economic Papers, 51, 120-32.

Artis, M.J., Krolzig, H.-M., Toro, J. (1999) The European business cycle, CEPR Discussion Paper No. 2242.

Artis, M.J., Bladen-Hovell, R.C, Osborn, D.R., Smith, G. And Zhang, W. (1995) Predicting turning points in the UK infation cycle, The Economic Journal, 105, 114564.

Barios, S., Brulhart, M. and Elliot R.J.R. (2002) A tale of two cycles: Co-fluctuations between UK regions and the Euro zone, The University of Manchester Discussion Paper No. 003.

Baxter, M. and King, R. (1999) Measuring business cycles: approximate band-pass filters for economic time series, Review of Economics and Statistics, 81, 575-93. 
Bhattacharya, R. and Binner, J.M. (1998) The shocking nature of output fluctuations in some EU countries, Applied Economics, 30, 1101-25.

Bikker, J.A. and Kennedy, N.O. (1999) Composite leading indicators of underlying inflation for seven EU countries, Journal of Forecasting, 18, 225-58.

Binner, J.M. and Wattam, S. (2003) A new composite leading indicator of inflation for the UK: a Kalman Filter approach, Global Business and Economics Review, 5, 242 $-64$.

Binner, J.M., Fielding, A. and Mullineux, A.W. (1999) Divisia money in a composite leading indicator of inflation, Applied Economics, 31, 1021-31

Binner, J.M., Bissoondeeal, R.K., Elger, T., Gazely, A.M. and Mullineux, A.W. (2005) A comparison of linear forecasting models and neural networks: An application to Euro inflation and Euro Divisia, Applied Economics, forthcoming.

Bloomfield, P. (1976) Fourier Analysis of Time Series: An Introduction, J. Wiley \& Sons Ltd.

Boughton, J.M. and Branson, W.H. (1991) Commodity prices as leading indicators of inflation, in Leading Indicator: New Approaches and Forecasting Records (Ed.) K. Lahiri and G.H. Moore, Cambridge, MA: Cambridge University Press, pp.305-338. 
Burns, A.F., and Mitchell, W.C. (1946) Measuring Business Cycles, Studies in Business Cycles, No. 2, Cambridge, MA: NBER.

Canova, F. (1999) Does detrending matter for the determination of the reference cycle and the selection of turning points? The Economic Journal, 109, 126-50.

Chatfield, C. (1996) The Analysis of Time Series: An Introduction, $5^{\text {th }}$ Edition, Chapman and Hall, New York.

den Butter, F.A.G., Coenen, R.L., van de Gevel, F.J.J.S. (1985) The use of ARIMA models in seasonal adjustment, Empirical Economics, 10, 209-30.

Drake, L., Mullineux, A.W. and Agung, J. (1997) One Divisia money for Europe. Applied Economics, 29, 775-86.

ECB. (1999a) The stability-oriented monetary policy strategy of the Eurosystem. ECB monthly Bulletin. January, 39-50.

ECB. (1999b) Euro Area monetary aggregates and their role in the Eurosystem's monetary policy strategy, ECB Monthly Bulletin, February, 29-46.

ECB. (2000) The two pillars of the ECB's monetary policy strategy, ECB Monthly Bulletin, November, 37-48. 
Elger, T. and Binner, J.M. (2004) The UK household sector demand for risky money. Berkeley Press Topics in Macroeconomics, 4, Article 3.

Fagan, G., Henry, J. and Mestre, R. (2001) An area-wide model (AWM) for the Euro Area, Working Paper Series 42, European Central Bank.

Ford, J.L. and Morris, J.L. (1996) The money multiplier, simple sum, Divisia and innovation-Divisia monetary aggregates: cointegration tests for the UK, Applied Economics, 28, 705-14 .

Gazely, A.M. and Binner, J.M. (2000) The application of neural networks to the Divisia index debate: evidence from three countries, Applied Economics, 32, 1607-15.

Harvey, A.C. (1991) Forecasting, Structural Time Series Models and the Kalman Filter, Cambridge University Press, Cambridge, UK.

Hodrick, R.J. and Prescott, E.C. (1997) Postwar US business cycles: An empirical investigation, Journal of Money, Credit and Banking, 29, 1-16.

Neftci, S.N. (1991) A time series framework for the study of leading indicators, in Leading Indicator: New Approaches and Forecasting Records (Ed.) K. Lahiri and G.H. Moore, Cambridge, MA: Cambridge University Press, pp. 57-62. 
Roth, H.L. (1991) Leading indicators of inflaiton, in Leading Indicator: New Approaches and Forecasting Records (Ed.) K. Lahiri and G.H. Moore, Cambridge, MA: Cambridge University Press, pp. 275-301.

Salazar, E., Smith, R., Weale, M. and Wright, S. (1995) Leading Indicators of UK Output. Unpublished manuscript, Department of Economics, University of Cambridge.

Serletis, A. and Krause, D. (1996) Nominal stylized facts of US business cycles, Federal Reserve Bank of St. Louis Review, 78, 49-54.

Serletis, A. and Atkins, F. (1988) The low-frequency relationship between money, prices and income. Applied Economics, 7, 877-87.

Stracca, L. (2004) Does liquidity matter?: Properties of a synthetic Divisia monetary aggregate in the Euro Area. Oxford Bulletin of Economics and Statistics, 66, 309-31. 


\section{Table Captions}

1. Table 1: Data definitions and sources for the Euro area.

2. Table 2: Data definitions and sources for the UK.

3. Table 3a: Cyclical properties of Euro area data.

4. Table 3b: Cyclical properties of UK data.

5. Table 4: Correlations of CLIs with inflation reference cycle for the Euro area and residual analysis.

6. Table 5a: Correlations of UK CLIs with inflation reference cycle for the UK and residual analysis.

7. Table 5b: Correlations of Euro-based UK CLIs with inflation reference cycle for the UK and residual analysis. 
Table 1: Data definitions and sources for the Euro area

\begin{tabular}{|c|c|c|c|c|}
\hline Variable & Original Series & Frequency & $\begin{array}{l}\text { Seasonally } \\
\text { adjusted at } \\
\text { source }\end{array}$ & Source \\
\hline $\mathrm{DM}^{\text {vii }}$ & Real Divisia M3 & Quarterly & Yes & Stracca (2004) \\
\hline SM3 & $\begin{array}{l}\text { Real Simple Sum } \\
\text { M3 }\end{array}$ & Quarterly & Yes & Stracca (2004) \\
\hline GDPDEF & GDP deflator & Quarterly & Yes & Stracca (2004) \\
\hline ENN & $\begin{array}{l}\text { Effective Exchange } \\
\text { Rate }\end{array}$ & Quarterly & Yes & $\begin{array}{l}\text { Fagan et al. (2001) ECB } \\
\text { Working Paper no. } 42\end{array}$ \\
\hline UNN & Unemployment & Quarterly & Yes & $\begin{array}{l}\text { Fagan et al. (2001) ECB } \\
\text { Working Paper no. } 42\end{array}$ \\
\hline ULC & Unit Labour Costs & Quarterly & Yes & $\begin{array}{l}\text { Fagan et al. (2001) ECB } \\
\text { Working Paper no. } 42\end{array}$ \\
\hline COMPR & Commodity Prices & Quarterly & Yes & $\begin{array}{l}\text { Fagan et al. (2001) ECB } \\
\text { Working Paper no. } 42\end{array}$ \\
\hline
\end{tabular}


Table 2: Data definitions and sources for the UK

\begin{tabular}{|c|c|c|c|c|}
\hline Variable & Original Series & Frequency & $\begin{array}{l}\text { Seasonally } \\
\text { adjusted at } \\
\text { source }\end{array}$ & Source \\
\hline DM4 $4^{\text {viii }}$ & Real Divisia M4 & Quarterly & No & Bank of England \\
\hline SM4 & $\begin{array}{l}\text { Real Simple Sum } \\
\text { M4 }\end{array}$ & Quarterly & No & Bank of England \\
\hline RPI & Retail Price Index & Monthly & No & DataStream \\
\hline IUV & $\begin{array}{l}\text { Import Unit Value } \\
\text { Index }\end{array}$ & Monthly & No & DataStream \\
\hline UNE & $\begin{array}{l}\text { Adult } \\
\text { Unemployment }\end{array}$ & Monthly & No & $\begin{array}{l}\text { Employment } \\
\text { Gazette/Labour Market } \\
\text { Trends }\end{array}$ \\
\hline VAC & $\begin{array}{l}\text { Vacancies at Job } \\
\text { Centres }\end{array}$ & Monthly & Yes & DataStream \\
\hline RSI & Retail Sales Index & Monthly & No & DataStream \\
\hline IIP & $\begin{array}{l}\text { Index of Industrial } \\
\text { Production }\end{array}$ & Monthly & Yes & DataStream \\
\hline GCP & $\begin{array}{l}\text { Global Commodity } \\
\text { Price Index }\end{array}$ & Monthly & No & DataStream \\
\hline
\end{tabular}


Table 3a: Cyclical properties of Euro area data

\begin{tabular}{llccc}
\hline Series & $\begin{array}{c}\text { Number } \\
\text { of Cycles }\end{array}$ & $\begin{array}{c}\text { Lead } \\
\text { Months }\end{array}$ & $\begin{array}{c}\text { Standard } \\
\text { Deviation }\end{array}$ & $\begin{array}{c}\text { Indicator } \\
\text { Classification }\end{array}$ \\
\hline Real Simple Sum M3 & 4.5 & 3 & 0.387 & Both \\
Real Divisia M3 & 4.5 & 48 & 0.354 & Both \\
Inflation & 4.5 & - & - & - \\
Effective Exchange Rate & 5 & 10 & 0.268 & Short \\
Unemployment & 3.5 & 21 & 2.40 & Long \\
Unit Labour Costs & 3.5 & 24 & 3.51 & Long \\
Commodity Prices & 4 & 27 & 1.57 & Long \\
\hline
\end{tabular}

Table 3b: Cyclical properties of UK data

\begin{tabular}{llccc}
\hline Series & $\begin{array}{c}\text { Number } \\
\text { of Cycles }\end{array}$ & $\begin{array}{c}\text { Lead } \\
\text { Months }\end{array}$ & $\begin{array}{c}\text { Standard } \\
\text { Deviation }\end{array}$ & $\begin{array}{c}\text { Indicator } \\
\text { Classification }\end{array}$ \\
\hline Real Divisia M4 & 2 & 31 & 23.5 & Both \\
Real Simple Sum M4 & 2 & 35 & 23.5 & Both \\
Inflation & 3.5 & - & - & - \\
Import Unit Value Index & 2.5 & 35 & 0.5 & Long \\
Adult Unemployment & 4 & 36 & 0.35 & Long \\
$\begin{array}{l}\text { Vacancies at Job Centres } \\
\text { Retail Sales Index }\end{array}$ & 3.5 & 20 & 0 & Short \\
$\begin{array}{l}\text { Index of Industrial } \\
\text { Production }\end{array}$ & 4.5 & 17 & 0 & Short \\
$\begin{array}{l}\text { Global Commodity Price } \\
\text { Index }\end{array}$ & 3 & 18 & 0 & Short \\
\hline
\end{tabular}


Table 4: Correlations of CLIs with inflation reference cycle for the Euro area and residual analysis

\begin{tabular}{|l|l|l|l|}
\hline CLIs & $\begin{array}{l}\text { Correlation with } \\
\text { Inflation Cycle }\end{array}$ & Weight $^{\text {ix }}$ & $\begin{array}{l}\text { Durbin } \\
\text { Watson }\end{array}$ \\
\hline SM3 Short & 0.99997636 & $\mathrm{P}$ & 0.025392 \\
DM3 Short & 0.99997902 & $\mathrm{P}$ & 0.016368 \\
SM3 Long & 0.99999548 & $\mathrm{P}$ & 0.000085 \\
DM3 Long & 0.99999567 & $\mathrm{P}$ & 0.000087 \\
\hline
\end{tabular}

Under the heading 'Weight', P indicates the component series of the CLIs were aggregated using principal components weights. 
Table 5a: Correlations of UK CLIs with inflation reference cycle for the UK and residual analysis

\begin{tabular}{|l|l|l|l|}
\hline CLIs & $\begin{array}{l}\text { Correlation with } \\
\text { Inflation Cycle }\end{array}$ & Weight & $\begin{array}{l}\text { Durbin } \\
\text { Watson }\end{array}$ \\
\hline SM4 Short & 0.99998924 & $\mathrm{E}$ & 0.000066 \\
DM4 Short & 0.99998926 & $\mathrm{E}$ & 0.000066 \\
SM4 Long & 0.99999046 & $\mathrm{E}$ & 0.000260 \\
DM4 Long & 0.99998906 & $\mathrm{E}$ & 0.000280 \\
\hline
\end{tabular}

Under the heading 'Weight', E indicates equal (unity) weights were used in the aggregation of the component series of the CLIs.

Table 5b: Correlations of Euro-based UK CLIs with inflation reference cycle for the UK and residual analysis

\begin{tabular}{|l|l|l|l|}
\hline CLIs & $\begin{array}{l}\text { Correlation with } \\
\text { Inflation Cycle }\end{array}$ & Weight & $\begin{array}{l}\text { Durbin } \\
\text { Watson }\end{array}$ \\
\hline SM4 Short & 0.99998879 & $\mathrm{E}$ & 0.000063 \\
DM4 Short & 0.99998890 & $\mathrm{E}$ & 0.000062 \\
SM4 Long & 0.99998754 & $\mathrm{E}$ & 0.000357 \\
DM4 Long & 0.99998674 & $\mathrm{E}$ & 0.000370 \\
\hline
\end{tabular}

Under the heading 'Weight', E indicates equal (unity) weights were used in the aggregation of the component series of the CLIs. 


\section{Appendix A}

The inflation reference cycle compared with Kalman generated DM3 Long CLI for Euro area..

Figure A.1 Divisia as Long Leading Indicator

Inflation reference cycle against Divisia long

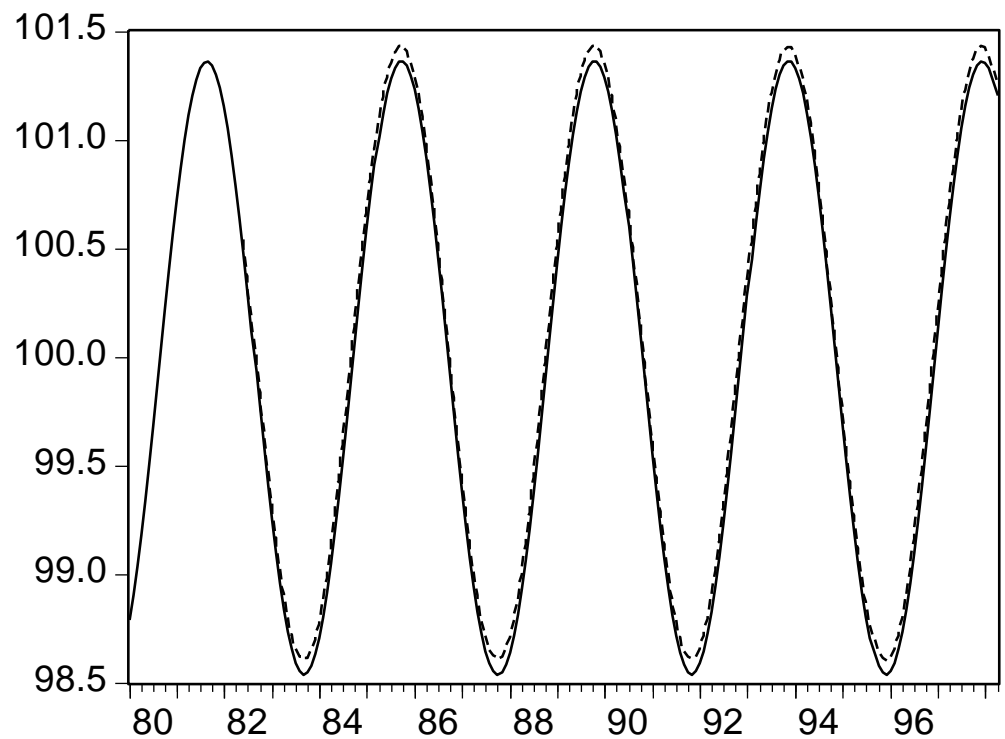

— Euro Inflation Cycle ---- DM3 Long

UK and Euro area inflation cycle compared

Figure A.2: UK and Euro inflation Cycle

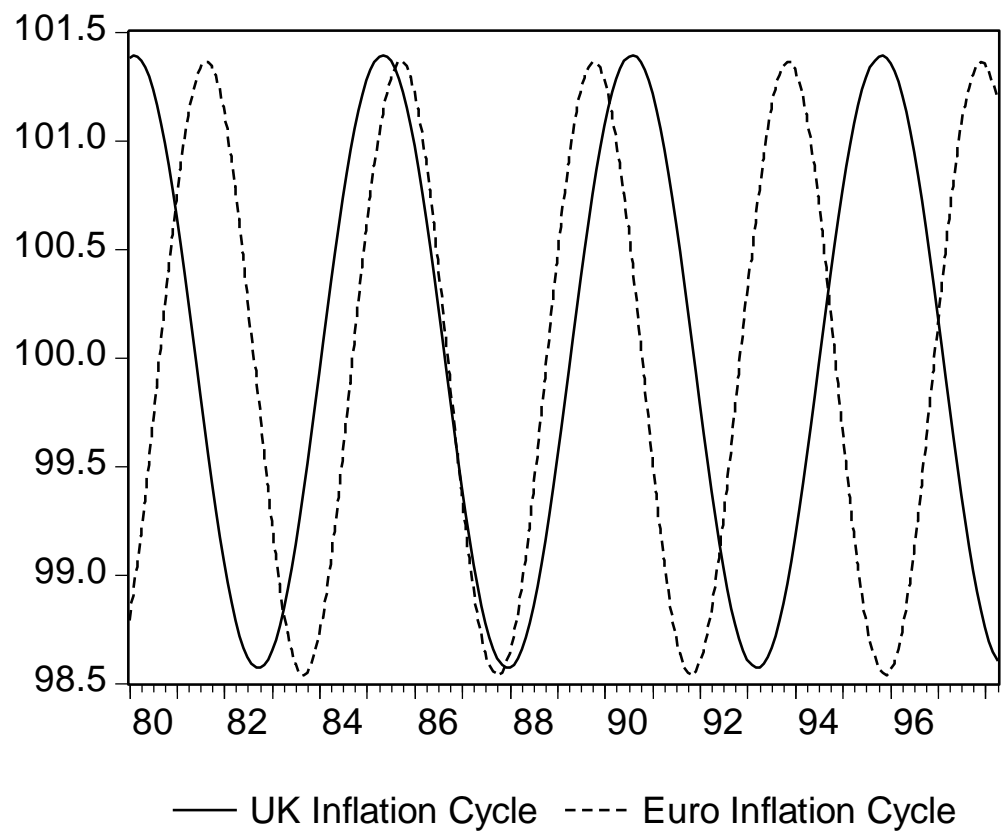


${ }^{\mathrm{i}}$ Other criteria in selecting component series are that they should also be quickly and regularly available and not be subject to major revisions (Neftci, 1991)

ii Following Artis et al. (1995) we use 'headline inflation' which is the annual percentage change in the seasonally unadjusted Retail Price index for the UK or GDP deflator for the Euro Area.

iii A multiplicative model is essentially the same as (3) on taking logs

${ }^{\text {iv }}$ In cases where the series have been seasonally adjusted at source only the irregular components are captured using the Census X-12 program.

${ }^{v}$ Not reported here for reasons of brevity but are available upon request from the authors.

${ }^{v i}$ The component CLI of, for example, UK SM4 Short CLI is Euro SM3 Short CLI and so on.

vii The asset components of the monetary aggregates SM3 and DM3 for the Euro area and their corresponding rates of return are taken from Stracca (2004). Simple Sum aggregates are constructed by simply summing the monetary components while the equations used in Drake et al. (1997) for constructing Divisia aggregates are used here for the Euro area Divisia aggregate. The asset components used in the construction of monetary aggregates are: currency, overnight deposits, short term deposits (other than overnight deposits) and marketable instruments. The benchmark rate used in this study is a 10-year government bond yield and we have added $2 \%$ points to it to avoid obtaining negative user costs.

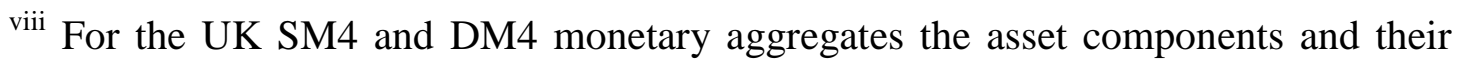
corresponding rates are obtained from the Bank of England website (http://www.bankofengland.co.uk/Links/setframe.html). The asset components are notes and coins, non-interest-bearing deposits, interest-bearing bank sight deposits, interest-bearing bank time deposits and building society deposits. The benchmark rate used is a three month local government deposit rate to which $2 \%$ points have been added to avoid obtaining negative user costs.

ix The weights obtained from principal component analysis are not given here for reasons of brevity but are available upon request from the authors. 